\title{
Penerapan Metode Prototype dalam Perancangan Sistem Informasi Penerimaan Karyawan Berbasis Website pada Berlian Agency
}

\author{
Ni Luh Ade Mita Rahayu Dewi ${ }^{1}$, Rukmi Sari Hartati ${ }^{2}$, Yoga Divayana ${ }^{3}$ \\ [Submission: 07-12-2020, Accepted: 02-03-2021]
}

\begin{abstract}
This research discusses the application of the prototype method in designing a website-based employee recruitment information system. The case study used in this research is Berlian Agency, which is a business in the field of digital services that serves various needs in the marketing sector such as website creation, social media management and so on. The research carried out is adjusted to the business processes that are running at Berlian Agency, as well as in accordance with ongoing events and current conditions. Therefore, researchers used a descriptive method in this study. The development method chosen is the prototype method. The application of the prototype method makes it easier to design research that aims to describe and explain objects based on existing conditions. In the prototype research method, there is a prototyping section that makes it easier for researchers to make the necessary designs. This study aims to produce an information system design for recruitment of employees. Based on the research results, this system has been successfully designed as expected so that the prototype that has been made can be used as a basis for continuing to work on the system to be made. The results of this design can be used as a blueprint or documentation for the company with the hope that later it can be used as literature to develop a real employee recruitment system.
\end{abstract}

Intisari- Pada penelitian ini membahas mengenai penerapan metode prototype pada perancangan sebuah sistem informasi penerimaan karyawan berbasis website. Study kasus yang digunakan dalam penelitian ini adalah Berlian Agency, yaitu sebuah sebuah usaha dibidang jasa digital yang melayani berbagai kebutuhan dibidang marketing seperti pembuatan website, sosial media management dan lain sebagainya. Penelitian yang dilakukan disesuaikan dengan proses bisnis yang berjalan pada Berlian Agency, serta sesuai dengan kejadian yang sedang berlangsung dan kondisi saat ini. Maka dari itu peneliti menggunakan metode deskriptif dalam penelitian ini. Metode pengembangan yang dipilih adalah metode prototype. Penerapan metode prototype mempermudah dalam perancangan penelitian yang bertujuan untuk mendeskripsikan dan menjelaskan objek berdasarkan kondisi yang ada. Pada metode penelitian prototype terdapat bagian prototyping yang membuat peneliti lebih mudah dalam membuat perancangan yang diperlukan. Penelitian ini bertujuan untuk menghasilkan sebuah

${ }^{1}$ Mahasiswa, Magister Teknik Elektro Universitas Udayana, Gedung Pascasarjana Universitas Udayana Jl. PB Sudirman Denpasar-Bali, Kode Pos: 80232; (tlp/fax: 0361239599; e-mail: mitarahayudewi97@ gmail.com)

${ }^{2,3}$ Dosen,Magister Teknik Elektro Universitas Udayana, Gedung Pascasarjana Universitas Udayana Jl. $P B$ Sudirman Denpasar-Bali, Kode Pos: 80232; e-mail: 2rukmisari@unud.ac.id, ${ }^{3}$ yoga@unud.ac.id) perancangan sistem informasi penerimaan karyawan. Berdasarkan hasil penelitian, sistem ini telah berhasil dirancang dengan baik sesuai yang harapkan sehingga prototype yang telah dibuat dapat digunakan sebagai dasar untuk melanjutkan pengerjaan sistem yang akan dibuat. Hasil rancangan tersebut dapat digunakan sebagai blueprint atau dokumentasi bagi pihak perusahaan dengan harapan nantinya dapat dijadikan sebagai sebuah literatur untuk mengembangkan sistem penerimaan karyawan sesungguhnya.

Kata Kunci- sistem informasi, penerimaan karyawan, metode deskriptif, metode prototype, website.

\section{PENDAHULUAN}

Berlian Agency merupakan sebuah usaha dibidang jasa digital yang melayani berbagai kebutuhan terutama dibidang marketing atau pemasaran seperti pembuatan website, sosial media management, berbagai digital ads dan lain sebagainya. Selama ini Berlian Agency telah banyak melayani perusahaan-perusahaan besar. Kini Berlian Agency telah semakin berkembang sehingga membutuhkan lebih banyak karyawan baru untuk membantu dalam menyelesaikan pekerjaan yang ada. Pada Berlian Agency, penerimaan karyawan masih menggunakan cara konvensional.

Penerimaan karyawan atau seleksi tenaga kerja adalah serangkaian metode yang dipakai untuk memilih karyawan baru yang akan dipilih untuk bekerja di suatu perusahaan. Penerimaan akhir tenaga kerja dilaksanakan oleh bagian departemen SDM sebagai hasil evaluasi terhadap proses seleksi tenaga kerja yang telah dilakukan dan tentunya melalui penggunaan prosedur-prosedur yang valid [1].

Penerimaan karyawan yang dilakukan secara konvensional menimbulkan beberapa permasalahan. Penerimaan karyawan mejadi tidak efisien karena admin harus membalas chat whatsapp dan email pendaftar satu persatu untuk diarahkan mengirim berkas lamaran ke email. Penerimaan karyawan baru secara konvensional juga dirasa tidak efektif karena membutuhkan waktu yang relatif lama bagi perusahaan mendapatkan kadidat yang tepat dikarenakan harus membalas dan menghubungi kandidat satu persatu. Berdasarkan permasalahan-permasalahan yang muncul, maka diperlukan suatu sistem yang dapat membantu Berlian Agency agar lebih mudah dalam melakukan perekrutan karyawan. Sistem yang dapat di buat adalah sebuah website penerimaan karyawan yang nantinya dapat disesuaikan dengan kebutuhan perusahaan.

Sebelumnya sudah pernah dilakukan penelitian dengan topik serupa yaitu berjudul "Rancangan Sistem Rekrutmen Karyawan Berbasis Web pada PT Fast Food Indonesia Region 
Pekanbaru". Pada penelitian tersebut diangkat masalah yang juga mengenai semua sistem penerimaan karyawan. Hasil dari penelitian ini adalah sebuah rancangan sistem rekrutmen karyawan berbasis web dengan menggunakan metode SDLC model Waterfall. Perbedaan dengan penelitian ini adalah pada penelitian tersebut menggunakan metode waterfall[2].

Penelitian dengan topik serupa yang kedua yaitu berjudul "Analisis dan Perancangan Sistem Informasi Perekrutan Karyawan Berbasis Web (Studi pada PT Sumber Abadi Bersama)". Pada penelitian tersebut masalah yang diangkat yaitu proses penerimaan karyawan pada PT Sumber Abadi Bersama. Penelitian ini menghasilkan sebuah rancangan sistem perekrutan karyawan berbasis website. Perbedaan dengan penelitian yang dilakukan juga terletak pada metode yang digunakan, yaitu metode waterfall [3].

Penelitian serupa yang ketiga berjudul "Perancangan Sistem Informasi Perekrutan Karyawan Berbasis Web Menggunakan Php Dan Mysql Di Pt. Ria Indah Mandiri”. Persamaan penelitian yang dilakukan adalah membahasa mengenai perekrutan karyawan dan sistem yang akan dibangun berbasis website. Perbandingan atau perbedaan dengan penelitian yang dilakukan adalah pada metode penelitian yang digunakan yaitu metode waterfal dan perancangan alur sistem yang digambarkan dengan use case diagram[4].

Berdasarkan permasalahan yang ada serta merujuk pada penelitian terdahulu, maka diputuskan sistem informasi yang akan dirancang pada penelitian ini adalah sebuah sistem informasi penerimaan karyawan berbasis website yang di dalamnya akan ada fitur register, login, pendaftaran karyawan dan pengumuman. Penggunaan website dipilih karena dengan website diharapakan para pelamar dapat menggunakannya dimanapun dan kapanpun selama terhubung dengan internet.

\section{Metode Penelitian}

\section{A. Metode Deskriptif}

Penelitian yang dilakukan disesuaikan dengan proses bisnis yang berjalan pada Berlian Agency serta berkaitan dengan peristiwa-peristiwa yang sedang berlangsung dan berkenaan dengan kondisi masa sekarang maka dalam penelitian ini peneliti menggunakan metode deskriptif. Nazir menjelaskan metode deskriptif adalah sebagai berikut:

Metode deskriptif adalah metode untuk memeriksa keadaan kelompok manusia saat ini, subjek, kondisi, sistem pemikiran, atau kategori peristiwa[5]. Tujuan penelitian deskriptif adalah mendeskripsikan atau melukiskan secara sistematis hubungan dari setiap kejadian yang dialami.

\section{A. Metode Prototype}

Perancangan sistem ini menggunakan metode prototyping [6].Prototyping merupakan proses yang digunakan untuk membantu pengembangan perangkat lunak dalam membentuk model perangkat lunak yang harus dibuat [7] [8] [9]. Prototype merupakan versi awal dari tahapan sebuah sistem software yang digunakan dalam mempresentasikan gambaran dari ide, eksperimen dari sebuah rancangan, mencari sebanyak mungkin masalah yang ada serta penyelesaian terhadap masalah tersebut [10]. Sistem dengan model prototype mengijinkan pengguna agar mengetahui seperti apa tahapan sistem dibuat sehingga sistem mampu beroperasi dengan baik. Metode prototype digunakan pada penelitian ini dimaksudkan untuk mendapatkan representasi dari pemodelan aplikasi yang akan dibuat [11]. Rancangan aplikasi awal mulanya berbentuk mockup selanjutnya akan dievaluasi oleh pengguna. Setelah mockup dievaluasi pengguna tahap selanjutnya mockup menjadi bahan rujukan bagi pengembang software untuk merancang aplikasi[12].

Metode prototype memiliki beberapa keuntungan sebagai berikut:

1. Prototype membuat pengguna terlibat dalam proses analisa dan juga desain.

2. Prototype mampu memahami segala yang dibutuhkan bukan secara abstrak melainkan secara nyata.

3. Dapat dipergunakan untuk memperjelas SDLC[13].

Terdapat beberapa tahapan dalam prototype. Berikut ini adalah tahapan-tahapan prototype:

1. Tahap Pengumpulan Kebutuhan

Format sotfware di definisikan secara bersama-sama oleh pengembang dan klien, begitu pula saat melakukan identifikasi kebutuhan serta sistem yang dibangun.

2. Tahap Prototyping

Tahap ini adalah tahap membuat perncangan sementara dengan focus pada keinginan pelanggan atau klien seperti membuat input dan ouput yang dibutuhkan.

3. Tahap Evaluasi Prototyping

Pada tahapan ini akan dilakukan pengecekan oleh klien terhadapt prototype yang telah dibangun dengan tujuan memastikan sistem yang telah dirancang telah sesuai dengan tujuan dan keperluan dari klien atau tidak. Apabila prototype yang dibangun belum sesuai maka akan dilakukan koreksi serta perbaikan dengan kembali pada tahap sebelumnya.

4. Tahap Mengkodekan Sistem

Prototype yang telah disetujui pada tahap sebelumnya akan mulai dibuatkan dalam bentuk kode atau koding pada tahapan ini, dengan menterjemahkannya kedalam bahasa pemrograman[14].

5. Tahap Pengujian Sistem

Sistem yang telah diubah kedalam bahasa pemrograman dan telah menjadi sebuah software akan diuji terlebih dahulu untuk menentukan apakah software telah dapat digunakan atau belum.

Pengujian yang dilakukan memiliki tujuan untuk memastikan kesalahan yang dihasilkan sistem seminimal mungkin. Biasanya digunakan pengujian Black Box, White box, Pengujian arsitektur, Basis path dan lain-lain.

6. Tahap Evaluasi Sistem

Pada tahap pengevaluasian ini dilakukan oleh klien untuk memastikan apakah program atau sistem yang sudah dibangun telah sesuai dengan keinginan atau belum. Apabila sudah maka sistem sudah dapat digunakan. Tapi apabila belum sesuai maka pengembang harus kembali ket tahap sebelumnya untuk memperbaiki ketidakseuaian itu.

7. Tahap Menggunakan Sistem

Sistem yang telah dibangun dan berhasil melewati tahap evaluasi sistem dengan baik sudah dapat digunakan. 


\section{HASIL DAN PEMBAHASAN}

\section{A. Analisa Kebutuhan}

Rancangan sistem inforasi penerimaan karyawan ini memiliki dua kebutuhan sistem. Kebutuhan fungsional sistem terdiri dari beberapa fungsi utama yang saling berkaitan dan saling mendukung satu sama lain. Sedangkan kebutuhan non fungsional sistem memiliki fungsi sebagai sarana pendukung agar kelancaran dari fungsi utama beroperasi sesuai dengan harapan.

1) Analisa Kebutuhan Fungsional: Dalam rancangan aplikasi sistem inforasi penerimaan karyawan terdiri dari dua akses, yaitu HRD dan Pelamar. Adapun kegiatan atau skenario yang dapat dilakukan oleh HRD dan Pelamar adalah sebagai berikut:

1. Skenario kebutuhan bagian HRD: login, melihat info pelamar, melihat info dokumen pelamar, mengelola daftar lowongan, mengelolah hasil seleksi.

2. Skenario kebutuhan bagian Pelamar: login, melihat info lowongan yang tersedia, mengisi data registrasi, mengelola lamaran, melihat hasil seleksi.

2) Analisa Kebutuhan Non Fungsional: Adapun yang termasuk kebutuhan non fungsional dalam perancangan ini adalah hardware dan software[15]:

1. Hardware

Spesifikasi perangkat keras (hardware) minimum yang dibutuhkan untuk sistem ini adalah.

Processor : $1.5 \mathrm{GHz}$ Dual core

Memory (RAM) : 2 GB DDR3

Hard disk : $120 \mathrm{~GB}$

Monitor : Resolusi Layar (1366 x 768)

Keyboard : QWERTY (86 keys)

Mouse : Optical

Printer : Ink Jet

2. Software

Spesifikasi perangkat lunak (software) minimum untuk menggunakan maupun merancang sistem ini sebagai berikut:

Sistem Operasi : Windows 7.

Xampp : beberapa komponen yang terdiri dari:

- Xampp Server, Versi Xampp Control Panel v.3.2.2

- Apache Server versi 2.4.3.

- Aplikasi MySQL Server Versi 5.1.36

- Aplikasi PHP Versi 5.3.0

Bahasa pemograman: PHP framework Codeigniter, HTML,

CSS, CSS framework Bootstraps, jQuery dan javascript

Text Editor : Visual Studio Code.

Database : Mysql

Web browser: Mozilla Firefox, Edge, Google Chrome, UC Browser, Opera.

\section{B. Mebangun Prototype}

Pada membangun prototype dibuat perancangan sementara dari software yang akan dibuat, rancangan yang dibuat adalah diagram konteks, ERD, konseptual database dan rancangan antarmuka.
1) Diagram Konteks: Pada diagram konteks berikut, dapat dilihat bahwa semua entitas eksternal mengirimkan informasi ke sistem atau dari sistem. Dimana terdapat aliran yang masuk ke sistem dalam arti sistem menerima masukan dari luar, dan aliran yang keluar dari sistem, artinya sistem memberikan informasi kembali ke bagian yang telah mengirimkan data masukan[16].

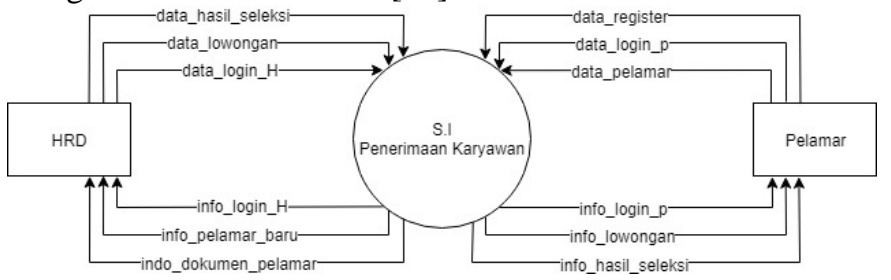

Gambar 1: Perancangan Diagram Konteks

Gambar 1 menggambarkan proses yang terjadi pada sistem informasi penerimaan karyawan, yang dimana HRD mengolah data lowongan, data pelamar, dokumen pelamar, info lowongan, dan penguman hasil seleksi. Pelamar dapat melakukan register dan pendaftaran.

2) DFD Level 0: Data flow diagram adalah suatu teknik grafis yang digunakan untuk menggambarkan informasi yang bergerak sebagai masukan ataupun keluaran pada sistem[17]. Berikut adalah diagram level 0 yang dirancang:

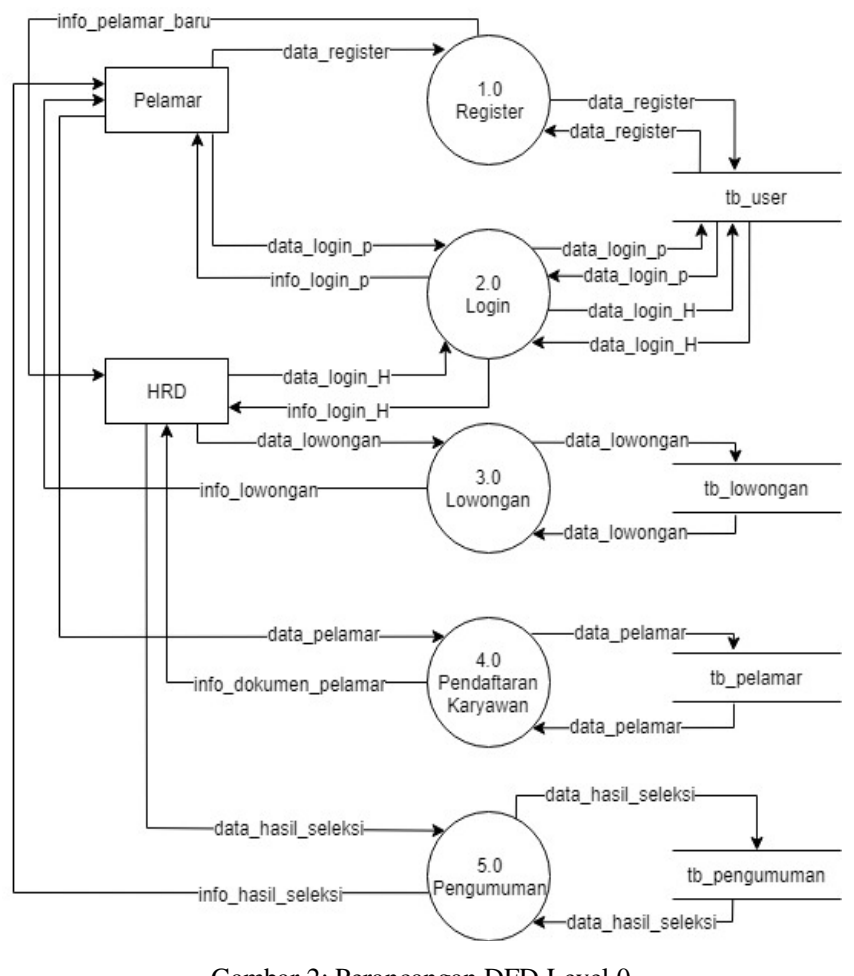

Gambar 2: Perancangan DFD Level 0

Gambar 2 menampilkan rancangan DFD level 0 dari sistem informasi penerimaan karyawan. Terdapat 5 proses yaitu register, login, lowongan, pendaftaran karyawan, pengumuman. Selain itu terdapat 4 data storage yaitu tb_user, tb_lowongan, tb_pelamar, dan tb_pengumuman.

Ni Luh Ade Mita Rahayu Dewi: Penerapan Metode Prototype dalam ... 
3) Basisdata Konseptual: Basisdata konseptual menggambarkan konsep atau skema database yang lebih spesifik mengenai kebutuhan kebutuhan terhadap data, dalam struktur database diperlukan konseptual untuk menyatakan keterhubungan dan batasan-batasannya[18]. Berikut adalah konseptual database yang dibuat.
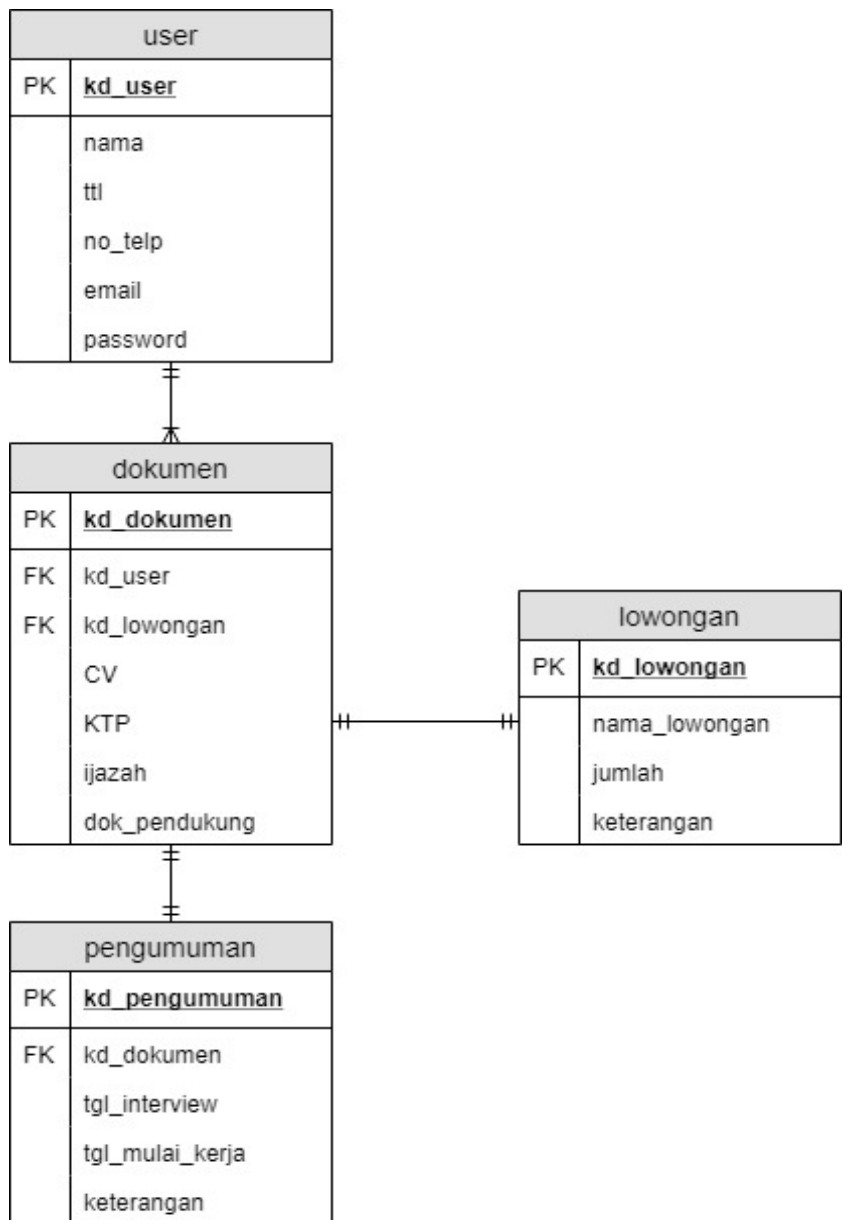

Gambar 3: Perancangan Basisdata Konseptual

4) ERD (Entity Relationship Diagram): Entity Relationship Diagram (ERD) adalah teknik yang digunakan untuk membuat sebuah model suatu sistem berdasarkan kebutuhan[19][20]. Berikut adalah gambaran rancangan ERD yang dibuat.

ERD pada gambar 4 menggambarkan ERD pada sistem informasi penerimaan karyawan, yang dimana terdapat 4 entitas pada ERD diatas yaitu user, dokumen, lowongan dan pengumuman. Keempat entitas ini memiliki relasi/hubungan dengan entitas lainnya. Entitas user dan HRD memiliki relasi ke login, user memiliki relasi ke produk, HRD memiliki relasi ke pemesanan.

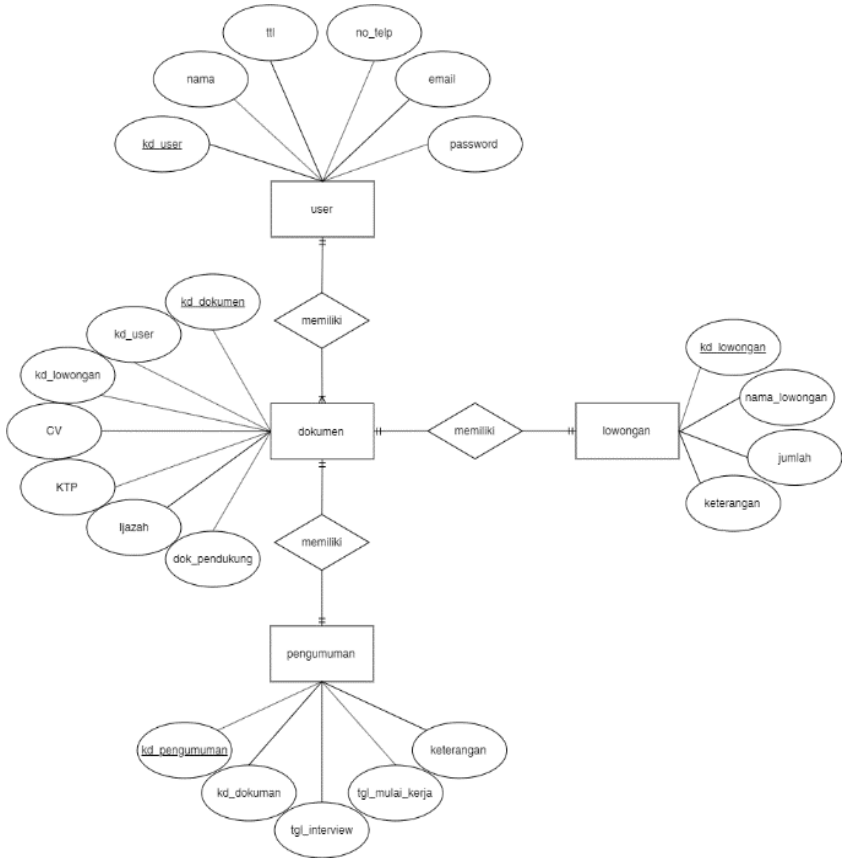

Gambar 4: Perancangan ERD (Entity Relationship Diagram)

5) Rancangan Antarmuka: Perancangan antarmuka merupakan gambaran dasar mengenai bentuk dan rancangan terhadap tampilan sistem yang akan dibuat nantinya. Perancangan ini berguna untuk mengetahui pembuatan tampilan pada sistem yang selanjutnya akan diimplementasikan[21]. Berikut adalah penjelasan dari masing masing rancangan desain antarmuka yang telah dibangun.

1. Halaman Register

Halaman register adalah halaman untuk menampilkan form register bagi calon pelamar yang ingin mejadi pengguna baru pada sistem penerimaan karyawan ini. Menu register hanya bisa diakses oleh calon pelamar.

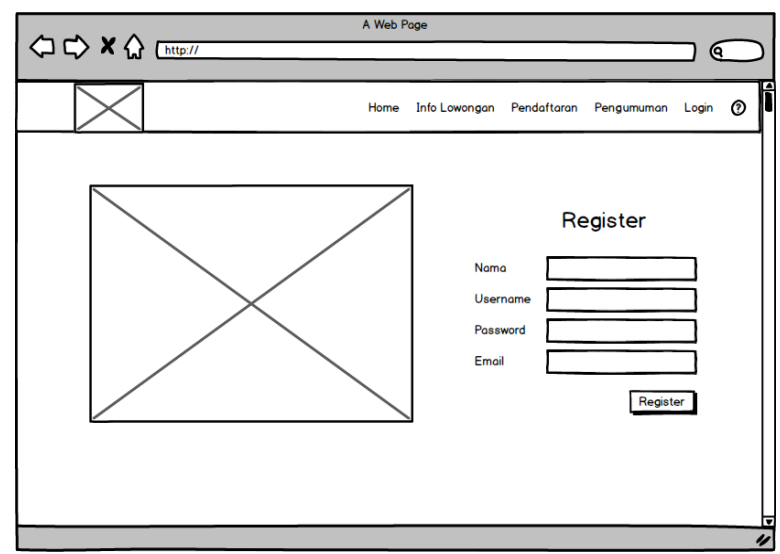

Gambar 5: Perancangan desain antarmuka untuk halaman register

2. Halaman Login

Halaman login adalah halaman untuk menampilkan form login yang dapat digunakan oleh HRD dan pelamar. Username dan password yang sesuai digunakan untuk masuk ke dalam sistem. Perancangan antarmuka halaman login dapat dilihat pada gambar 6 . 


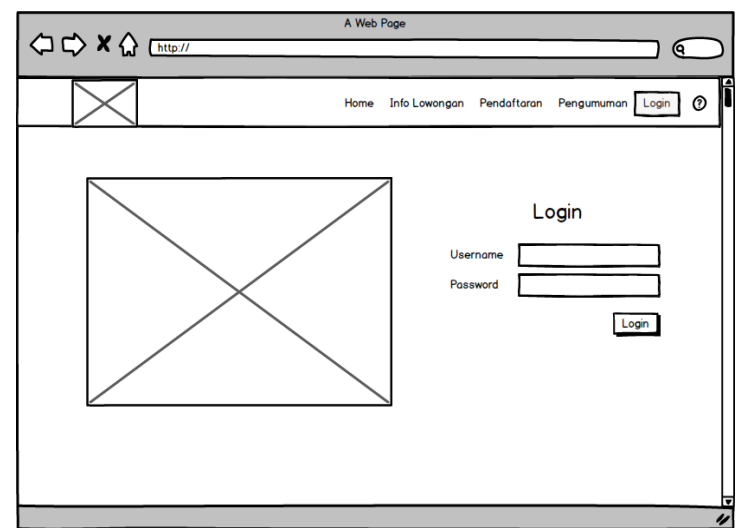

Gambar 6: Perancangan desain antarmuka untuk halaman login

\section{Halaman Home}

Halaman home adalah untuk menampilkan halaman pertama pada sistem, berisikan gambar slider dan sekilas info mengenai perusahaan. Gambar 7 akan menunjukan rancangan antarmuka dari halaman home.

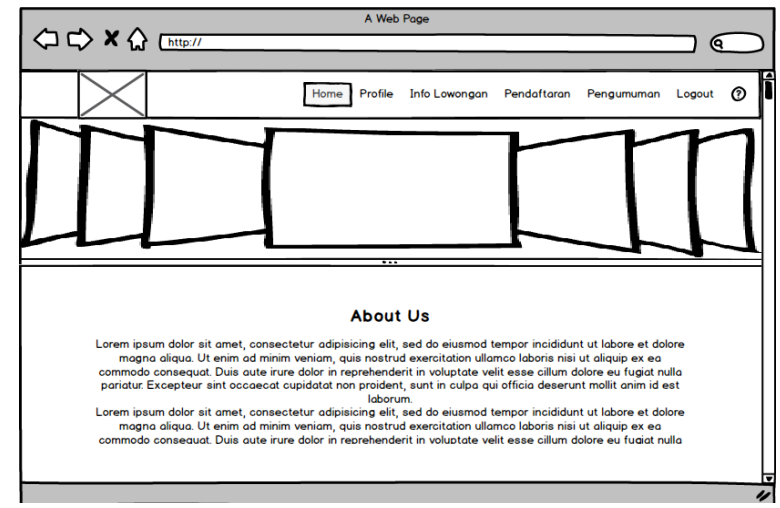

Gambar 7: Perancangan desain antarmuka untuk home

4. Halaman Info Lowongan

Halaman info lowongan adalah halaman yang menampilkan informasi mengenai lowongan pekerjaan yang tersedia di perusahaan. Gambar 8 akan menunjukan rancangan antarmuka dari halaman info lowongan.

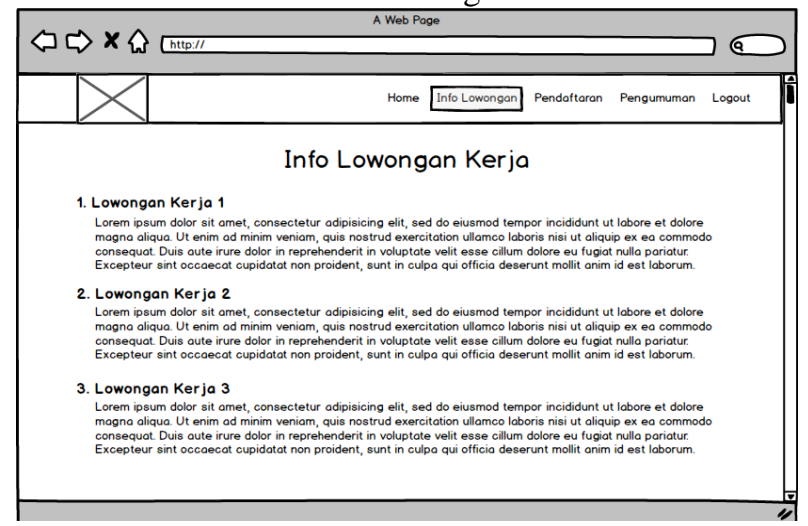

Gambar 8: Perancangan desain antarmuka untuk halaman info lowongan

\section{Halaman Pendaftaran}

Halaman pendaftaran adalah halaman yang menampilkan form pendaftaran bagi para calon pelamar. Form dilengkapi dengan data pelamar. Gambar 9 akan menunjukan rancangan antarmuka dari halaman pendaftaran.

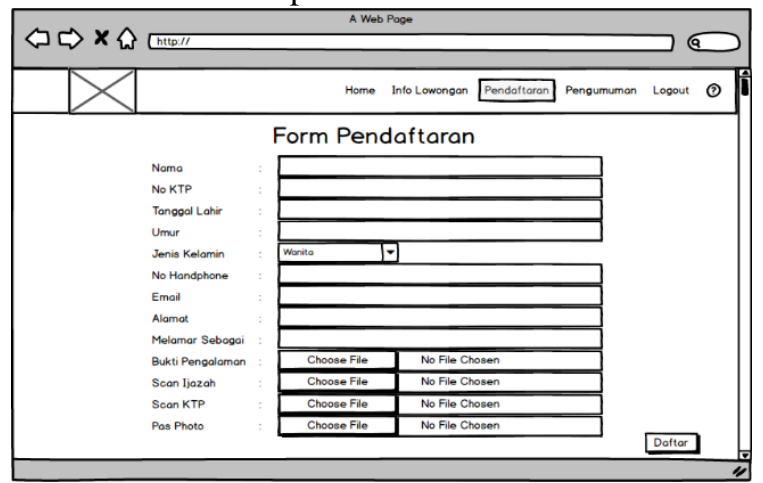

Gambar 9: Perancangan desain antarmuka untuk halaman pendaftaran

\section{Halaman Pengumuman}

Halaman penguman adalah halaman yang menampilkan informasi pengumuman mengenai hasil seleksi, jadwal interview serta informasi lainnya. Gambar 7 akan menunjukan rancangan antarmuka dari halaman pengumuman.

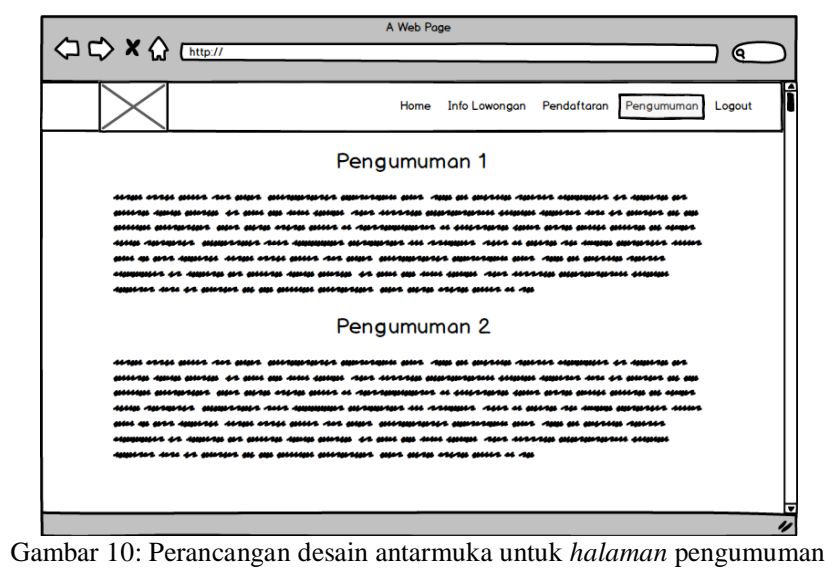

\section{KESIMPULAN}

Berdasarkan hasil penelitian yang telah dibahas, maka dapat disimpulkan bahwa perancangan sistem informasi penerimaan karyawan telah menghasilkan prototype rancangan yang digambarkan dengan diagram konteks, entity relationship diagram, konseptual database beserta rancangan interface. Prototype atau hasil rancangan yang telah di buat, nantinya dapat dijadikan sebagai acuan untuk mengembangkan sistem ke tahap pengkodean atau dapat digunakan sebagai dokumentasi oleh pihak Berlian Agency. Perancangan yang telah di buat dapat dievaluasi dan dikembangkan lebih lanjut agar sistem yang nantinya dibangun dapat menjadi jauh lebih baik. Dengan adanya sistem informasi perekrutan karyawan maka perusahaan dapat melakukan pemilihan calon karyawan dengan lebih efektif dan efisien.

\section{REFERENSI}

[1] M. A. Fermanta1, I M. A. Suyadnya2,dan N. M. A. E. D. Wirastuti, "Rancang Bangun Sistem Pendukung Keputusan Seleksi Tenaga Kerjaberbasis Web Menggunakan Metode Simple Additive Weighting

Ni Luh Ade Mita Rahayu Dewi: Penerapan Metode Prototype dalam ... 
Pada Pt. Solusi Lintas Data Cabang Bali," Majalah Ilmiah Teknologi Elektro., vol. 15, pp. 93-100, Des. 2016.

[2] Liza Trisnawati dan Evi Syarizal, "Rancangan Sistem Rekrutmen Karyawan Berbasis Web pad PT Fast Food Indonesia Region Pekanbaru", Jurnal Teknologi dan Sistem Informasi UNIVRAB. vol. 1, no. 1, 2016.

[3] Diyan Agus Permana dan Rizki Yudhi Dewantara, "Analisis dan Perancangan Sistem Informasi Perekrutan Karyawan Berbasis Web (Studi pada PT Sumber Abadi Bersama)", Jurnal Administrasi Bisnis. vol. 56, no 1, pp. 20-28, 2018.

[4] A. A. Rizky dan Irfan Ramdhani, "Perancangan Sistem Informasi Perekrutan Karyawan Berbasis Web Menggunakan Php Dan Mysql Di Pt. Ria Indah Mandiri,” Jurnal Manajemen Informatika, vol. 9, pp. 4957, April 2019.

[5] M.Linarwati1, A. Fathoni, dan M. M. Minarsih.," Studi Deskriptif Pelatihan Dan Pengembangan Sumberdaya Manusia Serta Penggunaan Metode Behavioral Event Interview Dalam Merekrut Karyawan Baru Di Bank Mega Cabang Kudus" Journal of Management, vol.2, Maret 2016.

[6] W. Nugraha dan M. Syarif,," Penerapan Metode Prototype Dalam Perancangan Sistem Informasi Penghitungan Volume Dan Cost Penjualan Minuman Berbasis Website." Jurnal Sistem Informasi Musirawas, vol. 3, pp. 97-105, Des. 2018.

[7] M. E. Siregar and D. Anyangsen, "Educational Game Application for Learning to Memorize Letters and Numbers Based on Android with the Prototype Method," J. Inov. Inform., Vol. 4, no. 2, pp. 1-8, 2019.

[8] E. Satria and R. Cahyana, "Development of an Android-Based Zakat Application Using the Prototype Method," J. Algoritm., Vol. 11, no. 2, pp. 213-219, 2017.

[9] O. Fajarianto, "Academic Service Prototype Against Mobile-Based Student Complaints," J. Lentera Ict, vol. 3, no. 1, pp. 54-60, 2017.

[10] Dwi Purnomo, "Model Prototyping Pada Pengembangan Sistem Informasi," Jurnal Informatika Merdeka Pasuruan, vol. 2, pp. 54-61, Agustus 2017.

[11] Yoko, P., Adiya, R., Nugraha, W., "Application of the Prototype Method in Designing a Website-Based SIPINJAM Application at the Credit Union Canaga Antutn.” Merati. Vol.7.pp 212-223. 2019.

[12] N.Putri, N. A. Prabowo, dan R.A.Widyanto, "Implementasi Metode Prototyping pada Perancangan Aplikasi Electronic Ticket (E-Ticket) berbasis Android." Jurnal Komtika (Komputasi dan Informatika), vol. 3. pp. 63-69, Nov. 2019.

[13] Wahyu W. Widiyanto, "Analisa Metodologi Pengembangan Sistem Dengan Perbandingan Model Perangkat Lunak Sistem Informasi Kepegawaian Menggunakan Waterfall Development Model, Model Prototype, Dan Model Rapid Application Development (Rad)," Jurnal INFORMA Politeknik Indonusa Surakarta, vol. 4, pp 34-40, 2018.

[14] R. Watson, "Language as category: using prototype theory to create reference points for the study of multilingual data," Lang. Cogn., vol. 11, no. 1, pp. 125-164, 2019.

[15] Nugraha, W., Syarif, M. "Application Of Prototype Methods In System Design Sales Volume Information And Calculation Of Costs Drink Website Based." JUSIM, vol.3,pp. 97-105. 2018.

[16] Lydia Helling,"Perancangan Sistem Informasi Pelayanan Pelanggan Pada Citra Laundry Bogor,' Jurnal Ilmiah Penelitian dan Penerapan Teknologi Sistem Informasi., vol.2,pp. 68-78, Feb. 2018.

[17] M. Muslihudin dan Oktafianto, Analisis dan Perancangan Sistem Informasi Menggunakan Model Terstruktur dan UML, Yogyakarta: ANDI, 2016.

[18] Henderi, Sistem Basis Data: Model Relasional, SQL, dan Object Oriented Database, Yogyakarta: Bintang Surya Madani, 2020.

[19] E. W. Fridayanthie, T. Mahdiati, "Rancang Bangun Sistem Informasi Permintaan Atk Berbasis Intranet (Studi Kasus: Kejaksaan Negeri Rangkasbitung)" Jurnal Khatulistiwa Informatika, vol. 4, pp. 126-138. Des. 2016.

[20] F. K. R. Sumantri, ,Hans F. Wowor., dan Arie Lumenta, "Sistem Informasi Anggota Jemaat GMIM Bethesda Ranotana Menggunakan Framework CodeIgniter" E-Journal Teknik Elektro dan Komputer. vol.5, pp. 21-28, Maret 2016.

[21] Rizky Lubis." Perancangan Antarmuka Aplikasi Berbasis Web Menggunakan User Centered Design Dalam Pembelajaran Keragaman Budaya." Jurnal Teknologi dan Sistem Informasi., vol.4, pp.1-6, Des 2017. 